\title{
A PRETREATMENT PROCEDURE FOR THE AMS RADIOCARBON DATING OF SUB-FOSSIL INSECT REMAINS
}

\author{
J A Tripp • T F G Higham ${ }^{1} \bullet$ R E M Hedges \\ Oxford Radiocarbon Accelerator Unit, Research Laboratory for Archaeology and the History of Art, Oxford University, \\ 6 Keble Road, Oxford OX1 3QJ, England.
}

\begin{abstract}
Two pretreatment methods for accelerator mass spectrometry (AMS) dating of insect remains were explored. One method involves a simple acid wash that removes carbonate, while the other is based on the industrial purification of chitin and results in isolation of polymeric chitosan. No contamination is observed from Maillard reactions during the deacetylation reaction used to isolate the chitosan. The methods were tested on Coleoptera samples from two Roman Britain sites. Our results demonstrate that both methods produce acceptable AMS dates that correspond well to the expected age of the deposits from which they came.
\end{abstract}

\section{INTRODUCTION}

Remains of insects are often found in an archaeological context and because many of them are temperature-sensitive organisms, they have been used as temperature and climate proxies in environmental studies (Robinson 2001). Accelerator mass spectrometry (AMS) radiocarbon dating is the most common method utilized to provide the chronological framework for these studies; however, it is typically associated with organic remains from peat or swamp material that are used for dating, not the insects themselves. This is often due to difficulty in obtaining pure material for dating.

For single-compound ${ }^{14} \mathrm{C}$ dating, the best candidate from insects is chitin or a derivative. Chitin (Figure 1) is a polymer composed of repeating $N$-acetyl-D-glucosamine units that is a major structural component of insect exoskeletons. In insects, chitin is bundled into microfibrils that are peripherally bound to proteins and arranged in a carbonate matrix to form the exoskeleton (Neville 1975). After death, the chitin-protein complex can undergo depolymerization or various condensation reactions with substances from the soil, resulting in numerous compounds, including humics, that may or may not be indigenous to or of the same age as the insects. While chitin is more resistant to diagenetic degradation when it is complexed to proteins, there is often significant chitin degradation even in cuticles that appear well-preserved (Stankiewicz et al. 1998). However, preservation of insect chitin under certain conditions in specimens as old as 25 million yr has been reported (Stankiewicz et al. 1997).

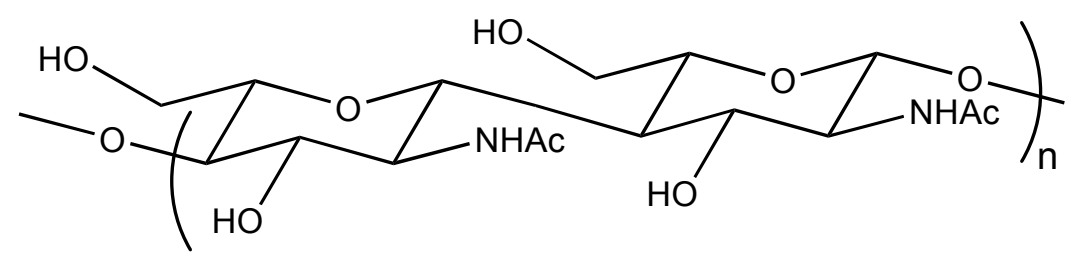

Figure 1 Structure of chitin

Certain limitations and requirements must be considered when developing a ${ }^{14} \mathrm{C}$ pretreatment procedure. Consistent, high recovery of pure material, with some way to assess the purity, is necessary. The procedure should not be too time-intensive and should use current protocols and techniques

${ }^{1}$ Corresponding author. Email: thomas.higham@archaeology-research.oxford.ac.uk.

(C) 2004 by the Arizona Board of Regents on behalf of the University of Arizona Proceedings of the 18th International Radiocarbon Conference, edited by N Beavan Athfield and R J Sparks RADIOCARBON, Vol 46, Nr 1, 2004, p 147-154 
where possible. In addition, isotope fractionation must be minimized. Previous work in our laboratory towards a pretreatment procedure for insects involved isolation of D-glucosamine from hydrolyzed chitin using ion-exchange chromatography, but this method identified serious problems of low recovery and incomplete purification (Hodgins et al. 2001). In addition, a significant and relatively consistent offset between AMS dates of insect remains and surrounding organic material was observed, and has also been reported by others (Elias and Toolin 1990; Elias et al. 1991; Walker et al. 2001). Possible explanations for this offset are different ecological and feeding adaptation of the insects, perhaps resulting in the uptake of differently aged ${ }^{14} \mathrm{C}$, or insufficient purification of the isolated chitin.

In this paper, we report a study comparing two purification methods. The first is a simple acid treatment to remove carbonate (Method A), while the other involves a harsher reaction to remove the protein component and isolate only the chitin polymer (Method B). This second method is based on the industrial purification of chitin (Roberts 1992) and involves the deacetylation, with concurrent deproteinization, of insect exoskeletons, followed by isolation of chitosan (deacetylated chitin) by a dissolution-precipitation procedure. The procedures were tested on Colepotera remains from two Roman-period sites in Britain.

\section{EXPERIMENTAL SECTION}

\section{Materials and Methods}

Commercial chitin, isolated from crab shells, was obtained from Aldrich. Water was purified using a Millipore Milli-Q system. All other solvents and reagents were purchased from Fisher Scientific. Coloeoptera remains were obtained by Dr Mark Robinson of the Natural History Museum at Oxford from the sites of Priors Gate and Godmanchester in Cambridgeshire, UK. Elemental and mass spectrometric analyses were undertaken using a Europa ANCA Roboprep CHN analyzer interfaced to a Europa 20/20 MS operating in continuous-flow mode. Graphite was prepared by reduction of $\mathrm{CO}_{2}$ over an iron catalyst in an excess $\mathrm{H}_{2}$ atmosphere at $560{ }^{\circ} \mathrm{C}$ prior to AMS ${ }^{14} \mathrm{C}$ measurement (Bronk Ramsey and Hedges 1999; Bronk Ramsey et al. 2000). Samples of insect chitin $<1.6 \mathrm{mg} \mathrm{C}$ in size were AMS dated as directly-injected $\mathrm{CO}_{2}$ using the ORAU gas ion source. $\delta^{13} \mathrm{C}$ values in this paper are reported with reference to VPDB and $\delta^{15} \mathrm{~N}$ results are reported with reference to AIR (Coplen 1994).

\section{Deacetylation of Commercial Chitin}

Chitin $(1.6 \mathrm{~g})$ was suspended in $50 \mathrm{~mL}$ of $50 \% \mathrm{NaOH}$ and heated to $120^{\circ} \mathrm{C}$ for $1 \mathrm{hr}$. The reaction was filtered and the solid resuspended in purified water. Next, the $6 \mathrm{M} \mathrm{HCl}$ was added to make the solution weakly acidic (about $\mathrm{pH} 3$ ) so that the solid dissolved. The solution was again filtered to remove any residual solids, and $6 \mathrm{M} \mathrm{HCl}$ added to the filtrate to make the solution strongly acidic $(\mathrm{pH}<1)$. A white solid (chitosan $\bullet \mathrm{HCl})$ precipitated from the solution. This was filtered, rinsed, dried, and analyzed.

\section{Maillard Reactions with Chitin and D-Glucosamine}

One-hundred g of chitin or D-glucosamine was mixed with $100 \mathrm{mg}$ of glycine (when used) and $10 \mathrm{~mL}$ of either water or $50 \% \mathrm{NaOH}$. The reactions were heated at $120^{\circ} \mathrm{C}$ for $1 \mathrm{hr}$. The neutral reactions were washed several times with water. Those with $\mathrm{NaOH}$ were filtered and acidified with $\mathrm{HCl}$ as described above. All samples were freeze-dried prior to analysis. 


\section{Preparation of Coleoptera Remains for ${ }^{14} \mathrm{C}$ Dating (Method A)}

The insect remains (elytra, pronotum, head capsules, and legs) were picked out of suspension under a microscope, and rinsed with acetone, methylene chloride, and acetone again, and dried under vacuum for $5 \mathrm{hr}$. The insect pieces were submerged in $0.5 \mathrm{M} \mathrm{HCl}$ for 3 days. They were then filtered, rinsed, and lyophilized.

\section{Preparation of Coleoptera Remains for ${ }^{14} \mathrm{C}$ Dating (Method B)}

The insect remains were treated as in Method A, but following removal of the acid, they were heated in $5 \mathrm{~mL} 50 \% \mathrm{NaOH}$ for $30 \mathrm{~min}$. The resulting product was filtered and the solids resuspended in water. The resulting solution was made weakly acidic by addition of $6 \mathrm{M} \mathrm{HCl}$, filtered to remove residual solids, and then made strongly acidic by further addition of $6 \mathrm{M} \mathrm{HCl}$. The resulting solids were captured in pre-combusted glass-fiber filters, lyophilized, and analyzed.

\section{Preparation of Seeds for ${ }^{14} \mathrm{C}$ Dating}

Carbonized and waterlogged woody seeds were prepared using the acid-base-acid (A-B-A) method (Hedges et al. 1989) to remove carbonates, fulvics, and humics, then rinsed and dried.

\section{RESULTS AND DISCUSSION}

\section{Deacetylation of Chitin}

In order to test the parameters for the deacetylation reaction in Method B, experiments were first performed on commercial chitin. Deacetylation (Scheme 1) results in a loss of two carbons from each residue, and thus, the $\mathrm{C} / \mathrm{N}$ ratio can be used to estimate the degree of deacetylation. A completely acetylated chitin chain will have a $\mathrm{C} / \mathrm{N}$ of 8 , while completely deacetylated chitin (chitosan) will have a $\mathrm{C} / \mathrm{N}$ of 6 . Using the $\mathrm{C} / \mathrm{N}$ ratio instead of the absolute values for $\% \mathrm{~N}$ and $\% \mathrm{C}$ eliminates the effects of residual moisture in this determination (Roberts 1992). A C/N less than 6 suggests the presence of proteins, which usually have $\mathrm{C} / \mathrm{N}$ between 2 and 6 . Proteins present in insect samples may be either indigenous or contaminating, and thus, their removal is important.

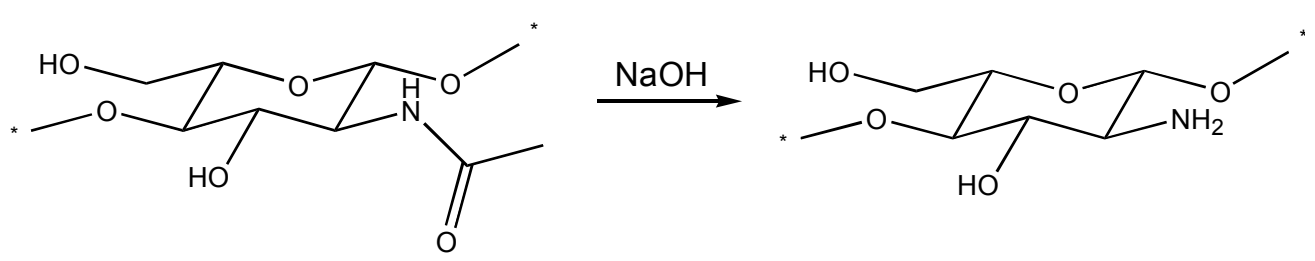

Scheme 1 Deacetylation of chitin

After deacetylation, the resulting chitosan polymer is soluble in weak acid, but will precipitate out of solution when strong acid is added due to the presence of multiple charges along the length of the polymer. It should be noted that the carbohydrate polymers are stable to even strong base, while similar conditions will result in cleavage of the amide backbone in proteins.

One necessary consideration for the deprotection reaction is the Maillard reaction, a condensation reaction that occurs between carbohydrates and amino acids that is responsible for a number of effects including the browning of cooked meat (Fayle and Gerrard 2002). The occurrence of Maillard reactions during the deprotection reaction may lead to covalent attachment of non-native and differently-aged proteins or amino acids onto the chitin. The mechanism of the initial steps of the reaction 
is shown in Scheme 2 using D-glucosamine as the substrate. The first step is a nucleophilic attack of the amine group of an amino acid on the anomeric carbon of the glycoside. This step can only occur on the linear form of the glycoside (2), and since polymerization requires the hemiacetal form (1), it suggests that if the chain integrity is preserved, no Maillard reaction will be observed. The inital product condenses to a Schiff base (4) and rearranges to form the Amadori product (6), which can then undergo numerous other reactive steps to produce a variety of highly colored products.

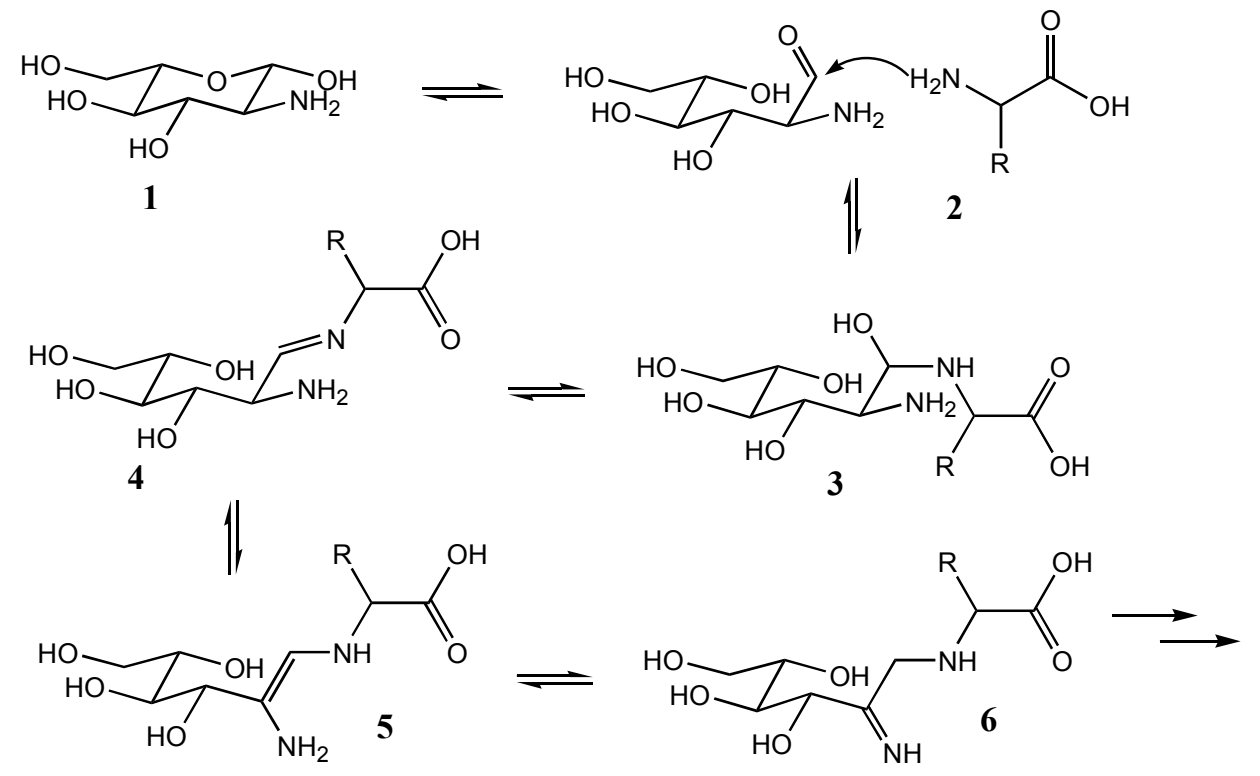

Scheme 2 First steps of Maillard reaction mechanism

We ran a series of experiments in which D-glucosamine and chitin were reacted under conditions I-IV listed below.

I. water

II. $50 \% \mathrm{NaOH}$

III. water + glycine

IV. $50 \% \mathrm{NaOH}+$ glycine.

The products of the Maillard reaction are highly colored, so this color change, as well as $\mathrm{C} / \mathrm{N}$ ratios of the resulting polymeric products can be used to determine if the reactions occurred or not. Elemental analysis was not undertaken on the D-glucosamine solutions because a range of compounds was formed, thwarting our attempts to isolate specific species for analysis.

As expected, all solutions containing D-glucosamine turned dark brown upon heating. The presence of base appeared to accelerate the reaction, as solutions II and IV changed color faster and became darker brown than reactions I and III. Even solutions that did not contain glycine (I and II) darkened significantly, probably due to a related reaction involving nucleophilic attack of the amino group of one D-glucosamine on another molecule using the same mechanism as shown in Scheme 2.

In contrast, the solutions containing chitin did not change color and showed little evidence of Maillard products. Results are shown in Table $1 . \mathrm{C} / \mathrm{N}$ ratios and stable isotope measurements show very little contamination of polymeric chitin from glycine which has significantly different values. This 
suggests that Maillard reactions of the chitin are unlikely to occur during the deacetylation reaction even with the presence of proteins and amino acids. In addition, the chitin chain does not appear to depolymerize under the reaction conditions.

Table 1 Elemental and isotopic results from Maillard reactions with chitin.

\begin{tabular}{lrrr}
\hline \multicolumn{1}{c}{ Conditions $^{\mathrm{a}}$} & $\mathrm{C} / \mathrm{N}(\sigma)^{\mathrm{b}}$ & $\delta^{13} \mathrm{C}, \%$ o $(\sigma)$ & $\delta^{15} \mathrm{~N}, \%$ o $(\sigma)$ \\
\hline I & $8.41(0.11)$ & $-23.01(0.19)$ & $-1.96(0.17)$ \\
II & $7.80(0.30)$ & $-22.52(0.28)$ & $-2.34(0.14)$ \\
III & $8.28(0.05)$ & $-23.04(0.14)$ & $-1.91(0.31)$ \\
IV & $7.23(0.32)$ & $-22.52(0.42)$ & $-2.17(0.39)$ \\
glycine $^{\mathrm{c}}$ & $2.04(0.01)$ & $-37.11(0.01)$ & $13.33(0.03)$ \\
\hline
\end{tabular}

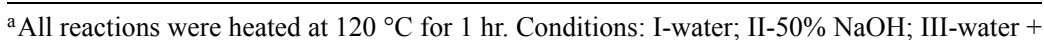
gly; IV-50\% $\mathrm{NaOH}+$ gly.

${ }^{b} \mathrm{n}=6$ for reactions $\mathrm{I}-\mathrm{IV}, \mathrm{n}=3$ for glycine.

${ }^{c}$ Data are given for the glycine used in reactions III and IV.

\section{${ }^{14} \mathrm{C}$ Dating of Coleoptera}

Coleoptera remains were obtained from wells at two Roman-era settlement sites in Cambridgeshire, England. The Priors Gate settlement is at the site of present-day Eaton Socon. A full analysis of the insect remains suggested that the area around the settlement was an open grassland or meadow, with trees growing in hedgerows and timber buildings (M Robinson, personal communication 2002). Pottery found in context with the Coleoptera was stylistically dated to the late 1st to 3rd century AD (Mepham and Loader 2001). The specimens were divided into 2 aliquots and treated with Methods $\mathrm{A}$ and $\mathrm{B}$ as described above.

Recovery, stable isotope, and AMS results are shown in Table 2. Clearly, Method B results in the loss of about $85 \%$ of the mass, but the increase in $\mathrm{C} / \mathrm{N}$ indicates that much of the lost material may be proteinaceous. The identical $\delta^{13} \mathrm{C}$ values indicate no carbon fractionation using the procedure. The uncalibrated AMS determinations for both procedures are indistinguishable within error and correlate well with the date of the pottery found in context with the Coleoptera. Calibrated age ranges $(\mathrm{AD} / \mathrm{BC})$ are shown in Figure 2 and these also demonstrate significant overlap.

Table 2 Elemental, isotopic, and AMS data for Coleoptera remains from Priors Gate. OxA-X-nnnn$n n$ numbers are given to the insect determinations because of their non-routine/experimental pretreatment chemistry.

\begin{tabular}{lllllll}
\hline OxA & Method $^{\text {a }}$ & Yield, $\%$ & $\mathrm{C} / \mathrm{N}$ & $\delta^{13} \mathrm{C}, \%$ & $\delta^{15} \mathrm{~N}, \%$ & ${ }^{14} \mathrm{C}$ age $(\mathrm{yr} \mathrm{BP})$ \\
\hline OxA-X-2020-21 & $\mathrm{A}$ & 100 & 5.6 & -25.9 & 9.7 & $1851 \pm 23$ \\
OxA-X-2039-11 & $\mathrm{B}$ & 15 & 7.2 & -25.6 & 4.5 & $1830 \pm 50$ \\
\hline
\end{tabular}

${ }^{\mathrm{a}} \mathrm{A}-\mathrm{acid}$ wash, B-full isolation of polymeric chitin (see text for details).

Further AMS determinations were obtained on Coleoptera samples from the London Road excavation of the Roman settlement at Godmanchester. Godmanchester was an active Roman settlement from the late 1st century to the 4th century AD (Jones 2003), although later activity seems to have been confined to inhumation cemeteries. It was a small settlement but had certain community buildings, including a forum and temples, suggesting that it may have functioned as a seat of local government. Evidence for farming wheat and for specialization of labor within the town (including animal husbandry and pottery production) was also found. 

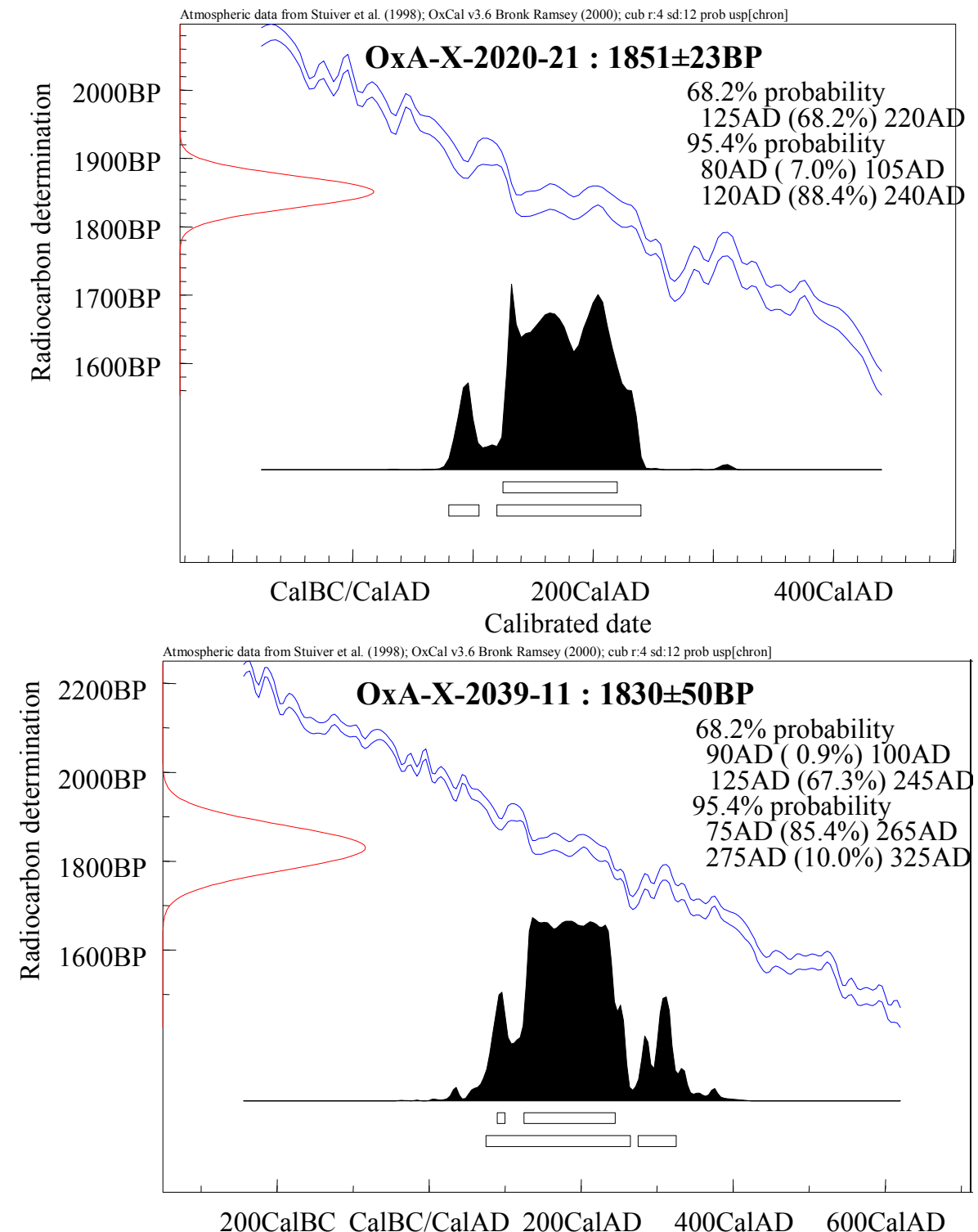

\section{Calibrated date}

Figure 2 Calibrated AMS dates obtained from Coleoptera from Priors Gate, Eaton Socon, Cambridgeshire, treated by Methods A and B.

AMS determinations of Coleoptera (Geotrupes and Aphodius) treated with Method A were compared with carbonized (Triticum spelta) and waterlogged (Malva sylvestris, Onopordum acanthium, Fallopia convolvulus) seeds found with them. Results are shown in Table 3. The three AMS determinations are statistically indistinguishable as a group [error weighted mean $=1716 \pm 19 \mathrm{BP}$ $\left.\left(T^{\prime}=5.55 ; \chi_{2: 0.05}^{2}=5.99\right)\right]$. Calibrated date ranges are shown in Figure 3, and correspond to the settlement era. 
Table 3 Elemental, isotope, and AMS data for Coleoptera remains and seeds from the Godmanchester site.

\begin{tabular}{llrlll}
\hline OxA number & Sample & $\mathrm{C} / \mathrm{N}$ & $\delta^{13} \mathrm{C}, \%$ & $\delta^{15} \mathrm{~N}, \%$ & ${ }^{14} \mathrm{C}$ age $(\mathrm{yr} \mathrm{BP})$ \\
\hline OxA-X-2040-22 & Coleoptera & 5.6 & -25.9 & 8.4 & $1764 \pm 29$ \\
12418 & Waterlogged seeds & 29.9 & -26.5 & 7.7 & $1690 \pm 32$ \\
12417 & Carbonized seeds & 18.0 & -23.2 & 6.5 & $1650 \pm 45$ \\
\hline
\end{tabular}

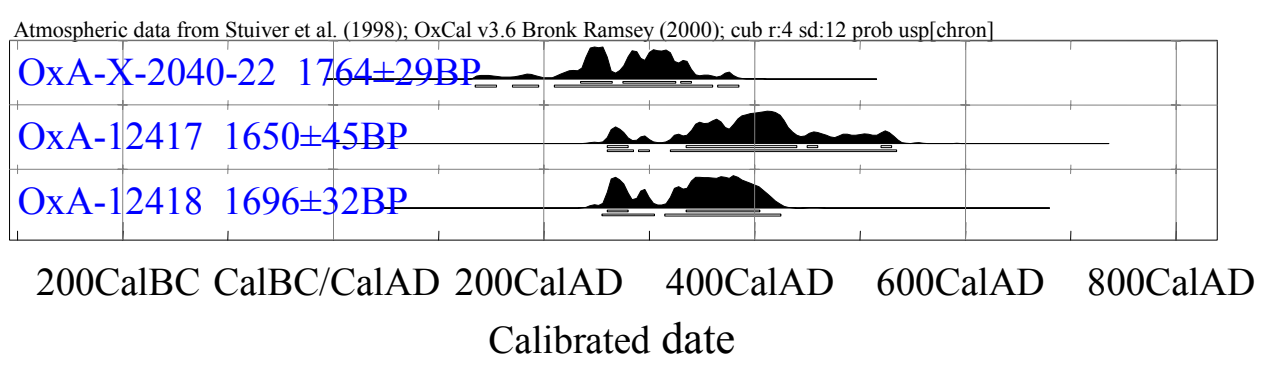

Figure 3 Calibration plots of AMS dates on beetles (OxA-X-2040-22) and carbonized (OxA-12417) and waterlogged (OxA-12418) seeds from Godmanchester, Cambridgeshire.

\section{CONCLUSION}

Our results suggest that a simple pretreatment method involving washing with organic solvents and treating the samples with acid is sufficient to yield accurate AMS dates in line with archaeological expectation. This method is simple and utilizes existing laboratory protocols. Future work will involve verification of this procedure using samples from other locations and of other ages.

Isolation of polymeric chitin is also a suitable technique, and appears to lead to ${ }^{14} \mathrm{C}$ determinations of the same age as insects purified using the simple acid wash. While this method does not result in pure isolated chitin, as seen by the $\mathrm{C} / \mathrm{N}$ ratios, it is a quick and simple way of purifying insect remains for AMS dating. The substance obtained is partially deacetylated chitin with little associated protein. Experiments suggest that the chain integrity is preserved during the reactions, and no external protein contamination via a Maillard mechanism was observed. The yield of this procedure will need to be improved before it can be used routinely, but it holds promise as a purification method for the most contaminated samples.

\section{ACKNOWLEDGEMENTS}

Funding from the National Science Foundation, USA (INT-0202648) is gratefully acknowledged. We also thank Dr Mark Robinson for providing samples for dating and for helpful discussion.

\section{REFERENCES}

Bronk Ramsey C, Hedges REM. 1999. Hybrid ion sources: radiocarbon measurements from microgram to milligram. Nuclear Instruments and Methods in Physics Research B 123:539-45.

Bronk Ramsey C, Pettitt PB, Hedges REM, Hodgins GWL, Owen DC. 2000. Radiocarbon dates from the Oxford AMS system: Archaeometry Datelist 30. Archaeometry 42:459-79.

Coplen TB. 1994. Reporting of stable hydrogen, carbon and oxygen isotopic abundances. Pure and Applied
Chemistry 66:273-6.

Elias SA, Toolin LJ. 1990. Accelerator dating of mixed assemblage of late Pleistocene insect fossils from the Lamb Spring site, Colorado. Quaternary Research 33: 122-6.

Elias SA, Carrara PE, Toolin LJ, Jull AJT. 1991. Revised age of deglaciation of Lake Emma based on new radiocarbon and macrofossil analysis. Quaternary Research 36:307-12.

Fayle SE, Gerrard JA. 2002. The Maillard Reaction. 
London: Royal Society of Chemistry. $116 \mathrm{p}$.

Hedges REM, Law IA, Bronk CR, Housley RA. 1989. The Oxford accelerator mass spectrometry facility: technical developments in routine dating. Archaeometry 31:99-113.

Hodgins GWL, Thorpe JL, Coope GR, Hedges REM. 2001. Protocol development for purification and characterization of sub-fossil insect chitin for stable isotopic analysis and radiocarbon dating. Radiocarbon 43(1): 199-208.

Jones A. 2003. Settlement, Burial and Industry in Roman Godmanchester, Excavations in the Extra-Mural Area: The Parks 1998, London Road 1997-8, and Other Investigations. BAR British Series 346. Oxford: Hadrian Books Ltd.

Mepham L, Loader E. 2001. Finds. In: Priors Gate, Bell Lane, Eaton Socon, St Neots, Cambridgeshire, Assessment Report on the Results of the Excavation. The Trust for Wessex Archaeology. p 11-4.
Neville AC. 1975. Biology of the Arthropod Cuticle. Berlin: Springer-Verlag. $448 \mathrm{p}$

Roberts GAF. 1992. Chitin Chemistry. Hong Kong: Macmillan Press Ltd. 368 p.

Robinson M. 2001. Insects as palaeoenvironmental indicators. In: Brothwell D, Pollard AM, editors. Handbook of Archaeological Sciences. London: John Wiley \& Sons. p 121-33.

Stankiewicz BA, Briggs DEG, Evershed RP, Flannery MB, Wuttke M. 1997. Preservation of chitin in 25million-year-old fossils. Science 276:1541-3.

Stankiewicz BA, Mastalerz M, Hof CHJ, Bierstedt A, Flannery MB, Briggs DEG, Evershed RP. 1998. Biodegradation of the chitin-protein complex in crustacean cuticle. Organic Geochemistry 28:67-76.

Walker MJC, Bryant C, Coope GR, Harkness DD, Lowe JJ, Scott EM. Towards a radiocarbon chronology of the Late Glacial: sample selection strategies. Radiocarbon 43(2B):1007-19. 